2007 110: 2316-2323

Prepublished online June 20, 2007;

doi:10.1182/blood-2007-02-074641

\title{
Alemtuzumab (Campath-1H) and CHOP chemotherapy as first-line treatment of peripheral T-cell lymphoma: results of a GITIL (Gruppo Italiano Terapie Innovative nei Linfomi) prospective multicenter trial
}

Andrea Gallamini, Francesco Zaja, Caterina Patti, Atto Billio, Maria Rosaria Specchia, Alessandra Tucci, Alessandro Levis, Annunziata Manna, Vicenzo Secondo, Luigi Rigacci, Antonello Pinto, Emilio lannitto, Valerio Zoli, Pierfederico Torchio, Stefano Pileri and Corrado Tarella

Updated information and services can be found at: http://bloodjournal.hematologylibrary.org/content/110/7/2316.full.html

Articles on similar topics can be found in the following Blood collections Clinical Trials and Observations (3511 articles)

Neoplasia (4217 articles)

Information about reproducing this article in parts or in its entirety may be found online at: http://bloodjournal.hematologylibrary.org/site/misc/rights.xhtml\#repub_requests

Information about ordering reprints may be found online at:

http://bloodjournal.hematologylibrary.org/site/misc/rights.xhtml\#reprints

Information about subscriptions and ASH membership may be found online at: http://bloodjournal.hematologylibrary.org/site/subscriptions/index.xhtml

Blood (print ISSN 0006-4971, online ISSN 1528-0020), is published weekly by the American Society of Hematology, 2021 L St, NW, Suite 900, Washington DC 20036.

Copyright 2011 by The American Society of Hematology; all rights reserved.

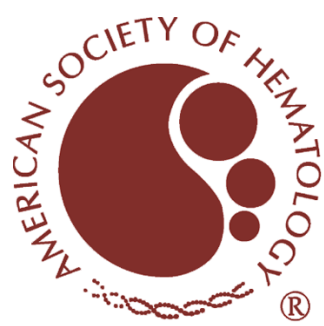




\title{
Alemtuzumab (Campath-1H) and CHOP chemotherapy as first-line treatment of peripheral T-cell lymphoma: results of a GITIL (Gruppo Italiano Terapie Innovative nei Linfomi) prospective multicenter trial
}

\author{
Andrea Gallamini, ${ }^{1}$ Francesco Zaja, ${ }^{2}$ Caterina Patti, ${ }^{3}$ Atto Billio, ${ }^{4}$ Maria Rosaria Specchia, ${ }^{5}$ Alessandra Tucci, 6 \\ Alessandro Levis, ${ }^{7}$ Annunziata Manna, ${ }^{8}$ Vicenzo Secondo, ${ }^{9}$ Luigi Rigacci, ${ }^{10}$ Antonello Pinto, ${ }^{11}$ Emilio lannitto, ${ }^{12}$ Valerio Zoli, ${ }^{13}$ \\ Pierfederico Torchio, ${ }^{14}$ Stefano Pileri, ${ }^{15}$ and Corrado Tarella ${ }^{16}$

\begin{abstract}
${ }^{1}$ Hematology Department, Ospedale Santa Croce, Cuneo; ${ }^{2}$ Hematology Department, Università di Udine, Udine; ${ }^{3}$ Hematology Department, Ospedale Cervello, Palermo, Sicily; ${ }^{4} \mathrm{Hematology}$ Department, Ospedale Regionale Generale, Bolzano; ${ }^{5} \mathrm{Hematology}$ Department, Ospedale Santa Giuseppe Moscati, Taranto; ${ }^{6} \mathrm{Hematology}$ Department, Ospedale Spedali Civili, Brescia; ${ }^{7}$ Hematology Department, Ospedale Santa Antonio e Biagio, Alessandria; ${ }^{8}$ Onco-Hematology Department, Ospedale Azienda Sanitaria Locale 5, La Spezia; Internal Medicine Department, Ospedale Galliera, Genova; ${ }^{10 H e m a t o l o g y ~ D e p a r t m e n t, ~}$ Università di Firenze, Firenze; ${ }^{11}$ Onco-Hematology Department, Ospedale Pascale, Napoli; ${ }^{12}$ Hematology Department, Università di Palermo, Palermo, Sicily; ${ }^{13} \mathrm{Hematology}$ Department, Ospedale Santa Camillo Forlanini, Roma; ${ }^{14}$ Medical Statistics Department, Università di Torino, Torino; ${ }^{15} \mathrm{Hemolymphopathology}$ Department, Università di Bologna, Bologna; ${ }^{16}$ Hematology Department, Università di Torino, Torino, Italy
\end{abstract}

To evaluate in a prospective multicenter trial the feasibility and clinical efficacy of the combination of alemtuzumab (Campath-1H) with the cyclophosphamide/doxorubicin/ vincristine/prednisone (CHOP) regimen (CHOP-C) as the primary treatment for patients with peripheral T-cell Iymphoma (PTCL), between January 2003 and December 2005, 24 consecutive patients with PTCL entered the study and received $8 \mathrm{CHOP}$ courses. Alemtuzumab was added at $30 \mathrm{mg}$ subcutaneously at day -1 initially to the first 4 courses ( 4 patients), and then to all 8 courses (20 patients). Complete remission (CR) was achieved in 17 (71\%) patients, 1 had partial remission, and 6 had stable/ progressive disease. At a median follow-up of 16 months (range, 5-42 months), 14 patients were alive, 9 had died from progressive disease, and 1 had died from pneumonia at day +198 while in CR. So far, 13 are disease-free, with an overall median duration of response of 11 months. The most frequent side effects were grade 4 neutropenia and cytomegalovirus (CMV) reactivation. Major infections were Jacob-Creutzfeldt
(J-C) virus reactivation, pulmonary invasive aspergillosis, Staphylococcus sepsis, and pneumonia. This study shows that CHOP-C: (1) is a feasible chemoimmunotherapy regimen; (2) is effective in PTCL with a high rate of CR achievement; and (3) is associated with mostly manageable infectious complications. This clinical trial was registered with the Osservatorio Nazionale sulla Sperimentazione cinica as ID no. 141202. (Blood. 2007;110:2316-2323)

(C) 2007 by The American Society of Hematology

\section{Introduction}

In western countries, peripheral T-cell lymphomas (PTCLs) account for $15 \%$ to $20 \%$ of aggressive lymphomas ${ }^{1}$ and for $7 \%$ to $10 \%$ of all the non-Hodgkin lymphomas (NHLs)., ${ }^{2,3}$ They usually occur in middle to advanced age with a peak incidence between the fifth and sixth decades, present as a widespread disease in more than two-thirds of the patients, and show an aggressive behavior, with more than half of the patients dying of their disease within 1 year. $^{2-4}$ Most authors agree about the comparatively grim prognostic outcome of the T-cell phenotype compared with a B-cell phenotype..$^{3,5-10}$ The former remains a negative prognostic factor in a multivariate analysis, and appears to be independent from the International Prognostic Index (IPI). ${ }^{11}$

The natural history of PTCL seems unaffected by secondand third-generation chemotherapy regimens, and the 5-year overall survival still remains between $25 \%$ and $47 \% .^{2-3,7-13}$ However, high-dose chemotherapy followed by autologous hematopoietic stem cell transplantation (ASCT) has been successfully performed in selected studies, mostly for resistant, recurring disease. ${ }^{14-19}$ Corradini et al, in a cohort of 62 patients with PTCL treated with a high-dose sequential program followed by ASCT as front-line therapy, definitely demonstrated no benefit of autologous bone marrow transplantation over standard chemotherapy. ${ }^{20}$

CD52 antigen is present on normal and pathologic B and T cells, with the highest values in T-prolymphocytic leukemia (T-PLL), as shown by Ginaldi et al using quantitative flow cytometry. ${ }^{21}$ In PTCL, however, CD52 expression varies from patient to patient, with an overall expression rate lower than $50 \% .^{22}$ Nevertheless, CD52 can be a suitable target for immunotherapy-based programs, given the availability of the anti-CD52 humanized monoclonal antibody alemtuzumab (Campath1H; Schering AG, Berlin, Germany). Thus, a prospective multicenter clinical trial was designed aimed to explore both the efficacy and the safety of a chemo-immunotherapy approach based on the combination of alemtuzumab with a standard-dose cyclophosphamide/doxorubicin/ vincristine/prednisone (CHOP) regimen as the first-line treatment for patients with PTCL.
Submitted February 15, 2007; accepted June 14, 2007. Prepublished online as Blood First Edition paper, June 20, 2007; DOI 10.1182/blood-2007-02-074641.

The publication costs of this article were defrayed in part by page charge payment. Therefore, and solely to indicate this fact, this article is hereby marked "advertisement" in accordance with 18 USC section 1734.

(C) 2007 by The American Society of Hematology 


\section{Patients and methods}

\section{Patients}

To be enrolled in the trial, patients had to meet the following criteria: (1) a histologic diagnosis of PTCL unspecified (PTCL-U), angioimmunoblasticlike T-cell lymphoma (AILD-T), or anaplastic large-cell T-cell lymphoma, Alk-negative (ALCLAlk ${ }^{-}$); (2) confirmation of the histopathologic diagnosis by the central review panel of expert pathologists of the University of Bologna or, alternatively, by a second expert pathologist of another referral center of pathology; (3) age greater than 16 years and less than 70 years; (4) absence of major heart, liver, kidney, or gastrointestinal (GI) dysfunction except those related to lymphoma; (5) written informed consent; (6) absence of uncontrolled infection; and (7) absence of other neoplasm or previous chemo-radiotherapy.

From June 2003 to December 2005, patients with a diagnosis of PTCL were consecutively enrolled in the trial by 14 Italian hematology institutions on behalf of GITIL (Gruppo Italiano Terapie Innovative nei Linfomi). Overall, 25 patients were enrolled and assessed for feasibility and toxicity; however, only 24 patients were evaluated for response, because 1 patient had a revised diagnosis of lymphoblastic lymphoma after pathologic review (see "Pathology review and CD52 expression").

\section{Pathologic review}

The pathologic material was available from 22 of the 25 enrolled patients and consisted of unstained sections $(n=4)$ or paraffin blocks $(n=18)$. The material was used for both diagnostic review and immunohistochemical localization of the CD52 molecule. In particular, the former was based on the evaluation of hematoxylin-eosin-stained preparations and a series of markers, including CD2, CD3, CD4, CD5, CD7, CD8, CD10, CD15, CD20, CD21, CD30, CD56, CD79a, PAX5/BSAP, and Mib-1. It should be noted that the markers could not be homogeneously assessed in all instances because for 4 of the patients, only 10 unstained sections were available. The corresponding antibodies were used following appropriate antigen retrieval and detected using the alkaline phosphatase antialkaline phosphatase (APAAP) complexes technique. ${ }^{23-24}$ Anti-CD52 (rat anti-human, monoclonal; Serotec, Oxford, United Kingdom) was applied at a 1:200 dilution and visualized with the EnVision ${ }^{+}$technique, as previously described. ${ }^{23}$ Prior to antibody exposure, the sections underwent antigen retrieval in citrate buffer $(\mathrm{pH}=6.0)$ in a microwave at $900 \mathrm{~W}$ ( 3 cycles lasting 5 minutes each). Two experienced pathologists (S.P. and C.C.) scored the CD52 results by estimating the number of positive cells. Patients were considered positive if $30 \%$ or more of the tumor cells were stained. ${ }^{24}$

\section{Study design}

Main protocol features. The study protocol was a phase 2, open-label trial performed among 14 Italian hematology institutions. The study was approved by the ethics committee of the coordinating center (Hematology Department of Cuneo Hospital) and subsequently approved by the local ethics committee of the individual centers and by the national clinical trials agency. Written informed consent was obtained according to the Declaration of Helsinki.

The primary end points of the study were feasibility and toxicity of the treatment program; the secondary end point was the efficacy of the program, assessed in terms of achievement of complete remission (CR), 1-year overall survival (OS), and 1-year failure-free survival (FFS).

To prevent excessive immunosuppression induced by alemtuzumab when administered once a month for 8 months, the treatment program was split into 2 therapeutic schedules, differing only in the number of alemtuzumab infusions, and stopping rules were introduced. Phase 1 consisted of 4 courses of CHOP-C (CHOP supplemented with alemtuzumab), and 4 courses of standard CHOP. Phase 2 followed, consisting of 8 courses of CHOP-C. The first 4 patients enrolled were allocated to phase 1 ; in the absence of a serious adverse event (SAE; see "Study design, stopping rules") in Phase 1, the study shifted to Phase 2 with the second group of patients. Had a single SAE been reported during phase 1, an additional patient would have been enrolled in this phase. If another patient within this group had developed a SAE, the trial would have been closed. The same protocol of stopping rules was planned for phase 2. A SAE was defined as any adverse event directly related to the therapy, occurring both during therapy or follow-up, including (1) death, (2) life-threatening complications, (3) disabling conditions, or (4) a prolonged hospitalization (more than 3 months).

Treatment schedule. The treatment schedule is summarized in Figure 1. In the first cohort of patients (patients 1-4: phase 1) alemtuzumab was given only at courses 1 through 4 , and standard CHOP was administered for courses 5 through 8 . In the second cohort (patients 5-25: phase 2), alemtuzumab was administered at all CHOP courses. Patients were given standard-dose CHOP chemotherapy for 8 courses as previously reported. ${ }^{25}$ Cycles were repeated every 28 days. At the first course, alemtuzumab was given subcutaneously with an escalated dose of $3 \mathrm{mg}, 10 \mathrm{mg}$, and $30 \mathrm{mg}$ on days $-2,-1$, and 0 , respectively, and the full $30-\mathrm{mg}$ dose was given the day before for subsequent courses. Chlorphenamine $(10 \mathrm{mg})$ was given intravenously 1 hour prior to alemtuzumab administration, along with $500 \mathrm{mg}$ paracetamole orally and $100 \mathrm{mg}$ alizapride intravenously, which were administered 30 minutes prior to alemtuzumab administration.

Sample size. A single-stage phase 2 study design was used to test the null hypothesis that the true response rate was $40 \%$ to $45 \%$ against the alternative that it was $70 \%$. A sample size of 25 evaluable patients was planned, using A'Hern's tables for exact single-stage phase 2 designs. ${ }^{26}$ If 15 or more responses were observed, the null hypothesis would be rejected. With this scenario, the probability of 1 -sided type I error was .05, and the study power was .90 .

Anti-infective prophylaxis. Prophylaxis against herpes simplex virus (HSV) and varicella-zoster herpes virus (HVZ), regardless of a history of previous recurrent disease, was given to all patients with $400 \mathrm{mg}$ acyclovir twice in a day. Prophylactic therapy against Pneumocystis carinii with $800 / 160 \mathrm{mg}$ sulphametoxazole-trimethoprim tablets twice a day on alternate days was given, or pentamidine aerosol every 45 days in case of allergic reaction to cotrimoxazole. Ciprofloxacin $(500 \mathrm{mg})$ twice a day was
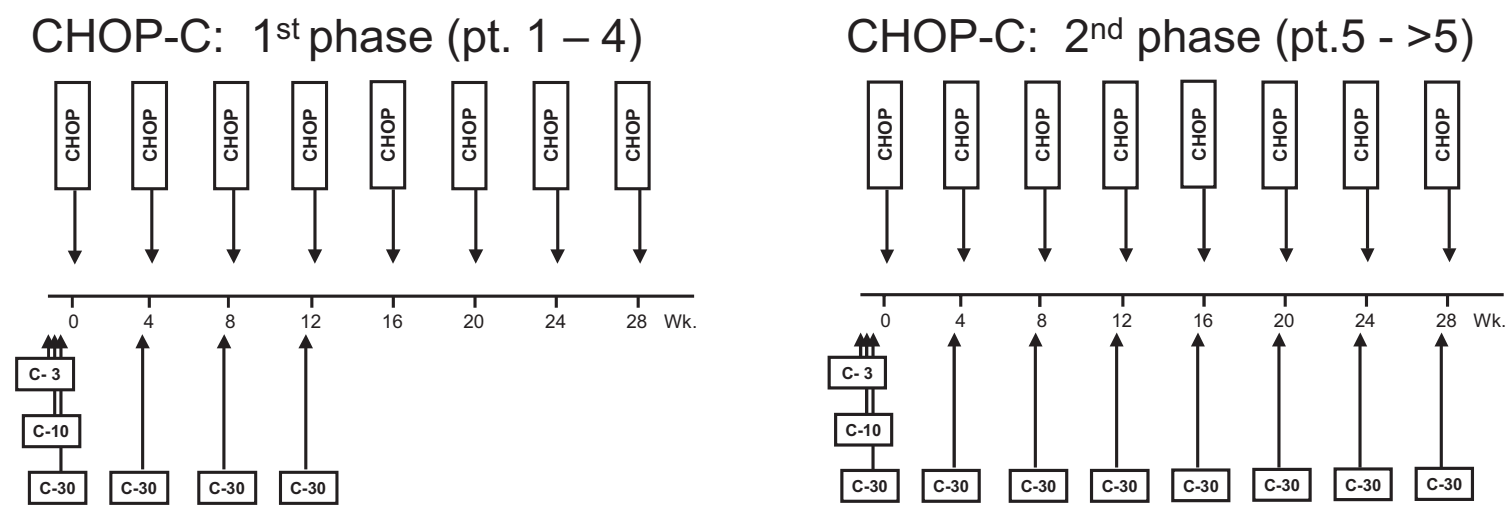

Figure 1. Two-phase schedule of CHOP-C administration. 
administered when neutrophil count decreased below $500 / \mu \mathrm{L}$. The galactomannan assay for monitoring invasive aspergillosis was performed twice a week in most patients, and $400 \mathrm{mg}$ /day itraconazole in oral solution, was administered during meals. Both galactomannan monitoring and antifungal prophylaxis were performed throughout the treatment and prolonged up to 6 months after the end of the chemotherapy. In case of 2 consecutive positive assays, antifungal therapy was started.

Stopping rules. As mentioned, the study was split into 2 phases based on the total dose of alemtuzumab administered and allowed for only 1 patient in phase 1 and 1 patient in phase 2 to present with a SAE. If any other patient beyond this threshold had developed a SAE, the study would have been closed. This protocol follows standard stopping rules as required for clinical trials conducted in good clinical practice.

\section{Disease evaluation}

Patients underwent a baseline staging with physical examination, involving a measurement of all the superficial pathologic nodes, complete blood count $(\mathrm{CBC})$, routine laboratory tests with liver and kidney function assessment, serologic testing for anamnestic viral and fungal infection, total and differential count of $\mathrm{CD}^{+}, \mathrm{CD}^{+}$, and $\mathrm{CD} 8^{+}$lymphocyte counts, chest and abdominal CT and/or positron emission tomography (PET) scan, and bilateral bone marrow trephine biopsy. The same hematologic, biochemical, and radiologic tests were repeated at the end of the therapy and every 6 months thereafter during follow-up. Bone marrow trephine biopsy was repeated in the presence of bone marrow invasion at diagnosis. The response assessment was made according to the Eastern Cooperative Oncology Group (ECOG) criteria of response to therapy for NHL..$^{27-28}$

\section{Statistical analysis}

All data were analyzed using the SAS program (SAS Institute, Cary, NC). ${ }^{29}$ OS and FFS curves were calculated according to the Kaplan-Meier method. ${ }^{30}$ OS was calculated from the date of diagnosis until death from any cause or date of last contact for living patients. For patients in CR, FFS was calculated from the date of diagnosis to the first evidence of failure. Failure was defined as (1) any treatment response different from CR or partial remission (PR), (2) disease relapse, (3) death from lymphoma, or (4) death from treatment effects.

\section{Results}

\section{Pathology review and CD52 expression}

The diagnosis of PTCL was confirmed by the central review panel in 19 of 22 patients, and defined according to the World Health Organization (WHO) Classification (8 with PTCL-U, 7 with AILD-T, 3 with ALCL Alk ${ }^{-}$, and 1 with enteropathy-associated T-cell lymphoma [EATCL]). ${ }^{3}$ The bioptic sample was insufficient in 2 patients, while the original diagnosis was not confirmed for 1 patient, who was diagnosed with T-lymphoblastic lymphoma $\left(\mathrm{TdT}^{+}\right)$at the pathologic review. In 3 patients ( 2 with PTCL-U and 1 with ALCL $\mathrm{ALK}^{-}$), the diagnosis was confirmed by the local referral pathologists. CD52 was analyzed in 19 of 24 patients. In 5 patients, a CD52 assay could not be done either for absence (3 patients) or insufficient material (2 patients). CD52 was evaluable in 15 of 19 patients, 11 that were $\mathrm{CD}_{2}{ }^{+}$and 4 that were $\mathrm{CD}_{52}{ }^{-}$. In the remaining 4 patients ( 2 with unstained sections and 2 with paraffin blocks available), antigen preservation was on the whole poor as shown by the immunohystochemical results for most antibodies used.

\section{Clinical characteristics of the patients}

The clinical characteristics of the 24 patients evaluable for both toxicity and response to $\mathrm{CHOP}-\mathrm{C}$ are reported in Table 1 . The
Table 1. Main patient characteristics

\begin{tabular}{lc}
\hline \multicolumn{1}{c}{ Parameter } & Value \\
\hline Number of patients & \\
Age, median y (range) & 24 \\
Histologic subtype, no. patients (\%) & $52(28-69)$ \\
PTCL-U & $14(58.3)$ \\
AILD-T & $6(25.0)$ \\
ALC-Alk & \\
EATCL & $3(12.5)$ \\
Ann Arbor stage III = IV, no. patients (\%) & $1(4.2)$ \\
$\quad$ III-IV & \\
B symptoms, no. patients (\%) & $21(87.5)$ \\
Bone marrow involvement, no. patients (\%) & $11(45.8)$ \\
Elevated LDH serum level, no. patients (\%) & $10(41.7)$ \\
IPI score, no. patients (\%) & $12(50.0)$ \\
0-1 & \\
2-3 & $8(33.3)$ \\
$4-5$ & $14(58.3)$ \\
\hline
\end{tabular}

${ }^{*}$ A total of 25 patients entered the study program and were evaluable for treatment feasibility and toxicity; however, 1 patient had a revised diagnosis of lymphoblastic lymphoma and was excluded from the response analysis.

mean age was 52.0 years (range, 28-69 years), and all but 3 showed advanced disease (stages III-IV). Bulky disease was recorded in 2 patients, bone marrow involvement in 10 patients, high lactose dehydrogenase (LDH) values in 12 patients, and an IPI of 0 in 1 patient, 1 in 7 patients, 2 in 7 patients, 3 in 7 patients, and 4 in 2 patients.

\section{Treatment feasibility and dose intensity}

Overall, 25 patients entered the study protocol and were valuable for treatment feasibility and toxicity. Patients 1 through 4 were treated with CHOP-C for 4 cycles, followed by 4 courses of standard CHOP; patients 5 through 21 received the planned 8 CHOP-C courses, while only 6 CHOP-C courses were delivered to patients 22 through 25 , as a result of individual physician decision.

The relative dose intensity (RDI) was calculated according to Hryniuk and Bush. ${ }^{31}$ The mean dose intensity was $210 \mathrm{mg} / \mathrm{m}^{2} /$ week $(\mathrm{RDI}=96 \%)$ for cyclophosphamide, $14 \mathrm{mg} /$ $\mathrm{m}^{2} /$ week (RDI $=90 \%$ ) for doxorubicin, $0.29 \mathrm{mg} / \mathrm{m}^{2} /$ week $(\mathrm{RDI}=94 \%)$ for vincristine, $85 \mathrm{mg} / \mathrm{m}^{2} /$ week $(\mathrm{RDI}=59 \%)$ for prednisone, and $8.0 \mathrm{mg} / \mathrm{m}^{2} /$ week for alemtuzumab (RDI $=88 \%$ ). In 1 patient, aged 69 years, vincristine was administered at half-dose for all CHOP-C courses ( $1 \mathrm{mg}$ every cycle). The RDI was slightly lower for alemtuzumab and prednisone because in 2 patients who developed invasive aspergillosis due to severe immunodepression, both drugs were reduced.

\section{Treatment response}

Response is summarized in Table 2. Among 24 evaluable patients, $17(71 \%)$ reached $\mathrm{CR}$ and 1 had PR, with an overall response rate $(\mathrm{CP}+\mathrm{PR})$ of $75 \%$; the remaining patients had either stable or progressive disease. All the patients affected by AILD-T (6 of 6), ALCL (3 of 3), and EATCL (1 of 1) entered CR, while only $50 \%$ of PTCL-U patients (7 of 14) showed a CR. CD52 expression could be evaluated in 15 patients: 4 were found negative and 11 positive. Two of the 4 patients with a CD52- ${ }^{-}$phenotype progressed during therapy and 2 patients entered CR, while 8 (73\%) patients with the CD52+ phenotype reached $C R$.

As shown in Table 2, after a mean follow-up of 495 days (range, 217-1186 days), 14 of 24 patients were still alive, and 
Table 2. Response to treatment of 24 evaluable patients with PTCL

\begin{tabular}{|c|c|c|}
\hline Response parameter & $\begin{array}{l}\text { Histopathology, } \\
\text { proportion }\end{array}$ & Total no. (\%) \\
\hline \multicolumn{3}{|l|}{ CR } \\
\hline PTCL-U & $7 / 14$ & $17(70.8)$ \\
\hline AILD-T & $6 / 6$ & - \\
\hline ALCL & $3 / 3$ & - \\
\hline EATCL & $1 / 1$ & - \\
\hline \multicolumn{3}{|l|}{ PR } \\
\hline PTCL-U & $1 / 14$ & $1(4.2)$ \\
\hline \multicolumn{3}{|l|}{ Minor response } \\
\hline PTCL-U & $1 / 14$ & $1(4.2)$ \\
\hline \multicolumn{3}{|l|}{ Disease progression } \\
\hline PTCL-U & $5 / 14$ & $5(20.8)$ \\
\hline \multicolumn{3}{|l|}{ Patients alive } \\
\hline PTCL-U & $5 / 14$ & $14(58.3)$ \\
\hline AILD-T & $6 / 6$ & - \\
\hline ALCL & $3 / 3$ & - \\
\hline Median follow-up, mo (range) & - & $16(5-42)$ \\
\hline \multicolumn{3}{|l|}{ Patients alive in CCR } \\
\hline PTCL-U & $5 / 14$ & $13(54.2)$ \\
\hline AILD-T & $5 / 6$ & - \\
\hline ALCL & $3 / 3$ & - \\
\hline Median follow-up, mo (range) & - & $11(5-42)$ \\
\hline
\end{tabular}

10 had died. Of the 24 patients, 17 achieved CR, 1 achieved PR, and 1 achieved minimal response (MR). A total of 5 patients showed progression early during therapy: 1 after 2 courses, 1 after 3 courses, and 3 after 4 courses. At the last follow-up December 31, 2006, 14 patients were alive. So far, 9 patients have died as a result of resistant lymphoma, including the 7 patients not in CR at the end of treatment and 2 patients in relapse; 1 more patient died from pneumonia while in $\mathrm{CR}$, 6 months after treatment completion; this complication could be a consequence of the immunosuppressive treatment and therefore considered as a treatment failure. A total of 13 patients are presently in continuous $\mathrm{CR}$, while 4 patients ( 3 in $\mathrm{CR}$ and 1 in $\mathrm{PR}$ ) experienced disease relapse at 3, 4, 5, and 8 months after treatment completion.

As shown in Figure 2A, the OS curve is projected to $70 \%$ and $53 \%$ at 1 and 2 years, respectively. As shown in Figure 2B, the FFS curve is projected to $54 \%$ and $48 \%$ at 1 and 2 years, respectively.

\section{Adverse events}

Toxicity was evaluated for all 25 patients who were treated with CHOP-C for a total of 176 courses.

Infusion-related. Infusion-related adverse events were recorded after alemtuzumab administration in 7 patients: a mild febrile spike (up to $38^{\circ} \mathrm{C}$ ) was transiently observed in 4 patients at different CHOP-C administrations, and 3 more patients occasionally displayed a local erythema around the injection site during the first 3 courses. No grade 4 reactions were observed.

Hematologic toxicity. Neutropenia was by far the most frequent manifestation of hematologic toxicity, with severe neutropenia recorded in 59 (34\%) of 176 cycles. Thrombocytopenia was less frequent, and severe thrombocytopenia was observed in only $4(2 \%)$ of 176 cycles. Anemia was even less frequent, and a reduction of more than $20 \mathrm{~g} / \mathrm{L}(2 \mathrm{~g} / \mathrm{dL})$ hemaglobin compared with the baseline values was recorded in $6(25 \%)$ of 24 patients at the end of treatment. The most severe hematologic toxicities were usually observed following the first CHOP-C course. Combined alemtuzumab and $\mathrm{CHOP}$ administration produced a profound decline in circulating T-lymphocytes: mean CD3, CD4, and CD8 values before treatment were 1042, 529, and 394 cells/ $\mu \mathrm{L}$, respectively, while these values dropped to 239, 156, and 305 cells $/ \mu \mathrm{L}$, respectively, after treatment. The values steadily increased thereafter and reached normal levels within 6 months in all but 2 patients.

Nonhematologic toxicity. Infectious complications were by far the most frequent nonhematologic toxicities (Table 3). Cytomegalovirus reactivation, without evidence of pneumonia, was diagnosed by immunofluorescent detection of p65-bearing leukocytes and/or viral DNA detection by polymerase chain reaction (PCR) analysis in at least 2 consecutive samples. With these diagnostic tools, CMV reactivation was detected in 15 (9\%) of 176 courses. All patients diagnosed with CMV reactivation received preemptive foscarnet or gancyclovir, usually with a rapid return to normal serologic results and disappearance of any symptoms possibly related to CMV reactivation. In 1 patient, left facial nerve palsy and hyposthenia in a left lower limb appeared 1 month after the completion of the chemotherapy: a cranial nuclear magnetic resonance (NMR) showed a picture evocative of J-C virus encephalitis, and the diagnosis was confirmed in cerebrospinal fluid (CSF) fluid by PCR. The patient is now in continuous CR but with a clinical picture of irreversible dementia: this complication is
A

Overall survival (24 pts)

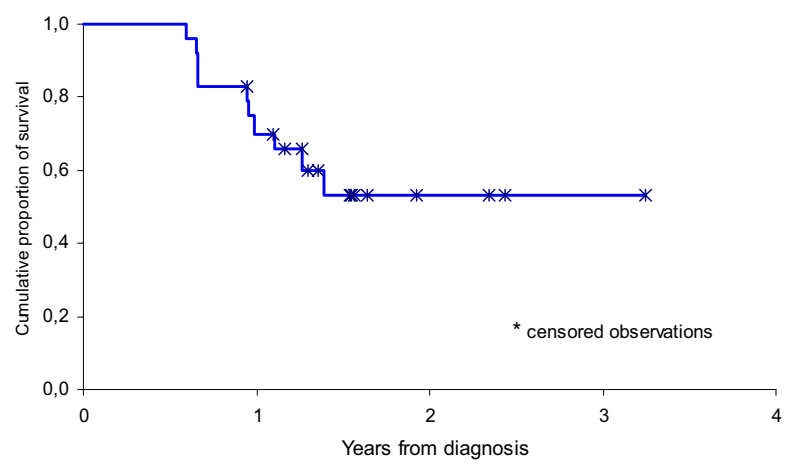

B

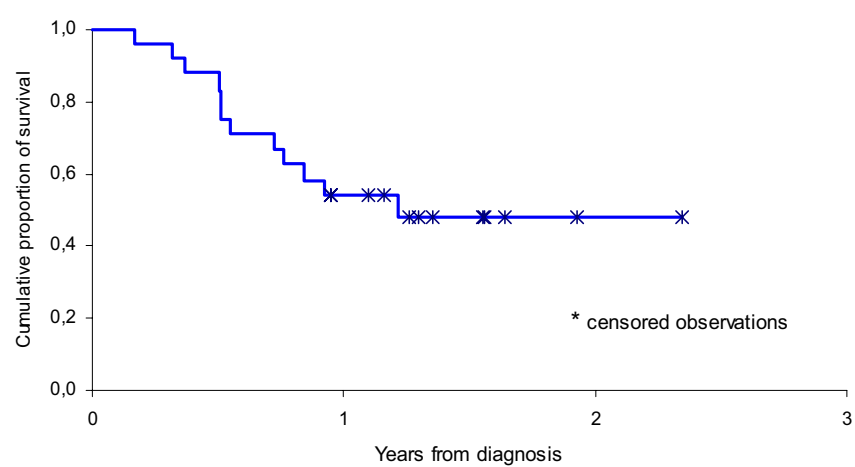

Figure 2. Kaplan-Meier estimates of distribution function of all 24 patients. (A) OS. (B) FFS. 
Table 3. Major (WHO 4) infections

\begin{tabular}{ccccc}
\hline Patient no. & CIC & Age, years & Histopathology & Infection \\
\hline 2 & UD1 & 57 & PTCL-U & Invasive aspergillosis, J-C viral encephalitis \\
4 & GE1 & 64 & ALK- & Staphylococcus sepsis, Streptococcus sepsis \\
7 & SP1 & 65 & PTCL-U & Bacterial pneumonia, PC pneumonia \\
15 & TO1 & 69 & PTCL-U & Bacterial pneumonia, invasive aspergillosis \\
\hline
\end{tabular}

related to the severe immunosuppression induced by the treatment and therefore should be considered a treatment failure. Two patients developed invasive aspergillosis. The first patient developed a lung infiltrate after the third CHOP-C course and was treated with voriconazole for 4 months with complete clearance of the lesion. This patient received a fourth CHOP course without alemtuzumab with approximately a 1-month delay, then received the remaining 4 courses regularly, all supplemented with alemtuzumab. The second patient developed pulmonary invasive aspergillosis after the fourth CHOP-C course, and underwent systemic antifungal therapy for a month, with a favorable outcome; this patient also resumed the therapy with a 1-month delay. One patient developed Pneumocistis carinii pneumonia, treated successfully with cotrimoxazole. Bacterial infectious complications included 1 patient with Staphylococcus aureus sepsis related to the surgical biopsy and 1 with Streptococcal sepsis; both responded to widespectrum antibiotics. There also was 1 patient with bacterial pneumonia sensitive to wide-spectrum antibiotics, occurring after the fifth cycle. Enlarged abdominal nodes were observed in 1 patient after the 8 CHOP-C courses: ultrasound fine-needle biopsy showed granulomatous adenopathy with Ziehl-Nielsen ${ }^{+}$ elements, probably related to atypical mycobacteriosis; however, re-evaluation 3 months later showed the almost complete disappearance of the abdominal nodes without any specific treatment. Finally, 1 patient developed fever of unknown origin (FUO) after the eighth $\mathrm{CHOP}-\mathrm{C}$ course that was resistant to empiric antibiotic therapy; the fever subsided upon resolution of neutropenia without any microbiological evidence of a specific etiologic agent.

Other mild side effects. A total of 3 patients showed signs of neurotoxicity: 2 presented a grade 2 obstinate constipation probably related to itraconazole, and 1 presented a grade 2 peripheral neuropathy.

\section{Discussion}

The present study reports the results of a prospective multicenter trial to evaluate the feasibility, safety, and efficacy of the combination of alemtuzumab and CHOP (CHOP-C) as first-line treatment for patients with PTCL. Alemtuzumab was used at a low dosage of $30 \mathrm{mg}$ per CHOP course, which helped make the program feasible. Indeed, CHOP-C was deliverable to all patients, with minor dose reductions in a few instances. Nevertheless, infectious complications were not only frequent but also severe and life-threatening in a few patients. On the other hand, alemtuzumab given at $30 \mathrm{mg}$ along with CHOP-C produced a high rate of stable CR. This result is quite encouraging and suggests that chemo-immunotherapy may represent a major advance in the management of PTCL, provided that careful monitoring and prompt treatment of infectious complications are implemented in those new schedules that include alemtuzumab.

The term PTCL designates an heterogeneous group of T-cell malignancies characterized by an aggressive behavior and a dismal prognosis, with less than $30 \%$ of patients being cured by anthracycline-containing therapies, such as CHOP or CHOPlike regimens, ${ }^{2-4,8-9,12}$ Because of these disappointing results, other strategies have been explored, including high-dose chemotherapy and autografting. So far, most of the published studies with ASCT both as salvage or first-line therapy have failed to show any significant advantage over standard treatment with standard chemotherapy (CHOP or CHOP-like regimens). ${ }^{13-18,20,32}$ Two recent publications have prospectively explored the role of ASCT as a first-line treatment after high-dose chemotherapy in an intent-to-treat and long-term analysis, and both failed to show any advantage over standard treatment. ${ }^{20,33}$ Chemoimmunotherapy combining antilymphoma cell monoclonal antibody and chemotherapy is presently the most innovative and effective approach in the management of lymphoma, specifically B-cell subtypes. ${ }^{34-36}$ The CD52 antigen seems a suitable target for chemo-immunotherapy programs for PTCL, given the availability of the anti-CD52 alemtuzumab. The glycosylphosphatidylinositol-anchored membrane glycoprotein CD52 is detectable by cytofluorimetric assay on normal and pathologic B- and T-cell populations, with the highest values observed in some T-cell neoplasms such as T-PLL, although the expression of this molecule has been found detectable in less than $50 \%$ of PTCL samples evaluated using a standard immunohistochemical procedure. ${ }^{21-22}$

The inclusion of alemtuzumab in therapeutic programs for T-cell disorders has been considered with increasing interest in the last few years. Preliminary observations have shown some promising results in different $\mathrm{T}$-cell malignancies, including T-PLL, cutaneous T-cell lymphomas, and T-cell large granular lymphocytic leukemia. ${ }^{37-40}$ So far, a single study has been performed with alemtuzumab in PTCL in a series of 14 patients with PTCL failing 1 or 2 lines of chemotherapy. Alemtuzumab was given alone at $30 \mathrm{mg}$ subcutaneously 3 times a week for a maximum of 12 weeks and produced an overall response rate of $36 \%$, with 3 patients achieving CR and 2 patients achieving PR. Despite these encouraging results, the study was closed because of unacceptably high toxicity, with 5 treatment-related deaths. ${ }^{41}$ Quite recently, a very preliminary report has been published on 20 patients treated with CHOP-C with the same schedule of the present study, with courses repeated every 21 days. The $\mathrm{CR}$ rate was $65 \%$, and the estimated event-free survival at 1 year was $43 \% .{ }^{42}$ These results, albeit similar to ours, are the report of an interim analysis of an ongoing trial and are too preliminary for a comment.

These considerations taken together prompted us to design a prospective trial to evaluate alemtuzumab in combination with chemotherapy in PTCL. In planning the trial, we carefully considered the following main issues: (1) the very aggressive behavior of PTCL; (2) the potential risks of infectious complications with alemtuzumab; (3) the need to combine alemtuzumab with a chemotherapy program well defined for both toxicity and clinical efficacy; and (4) the unequivocal histopathologic diagnosis of PTCL of patients entering the study protocol. Thus, a 
study protocol was designed for patients with PTCL at disease onset; the program included the use of a standard CHOP regimen supplemented with alemtuzumab. To prevent excessive immunosuppression, the dose of alemtuzumab was $30 \mathrm{mg}$ in each course, which represents a much lower dosage compared with that used in previous studies; the cycles were administered every 4 weeks instead of 3 weeks. A histopathologic review of the diagnostic sample was performed in all instances.

Combining alemtuzumab with standard CHOP chemotherapy proved to be quite effective in terms of treatment response: 18 patients responded with an overall response rate of 75\%: 17 patients entered CR, and 1 entered PR. Of the 17 patients in CR, the response was durable in 14 patients, with a median CR duration of 11 months. This result compares favorably with the less than $50 \% \mathrm{CR}$ rate reported with $\mathrm{CHOP}$ or CHOP-like regimens. ${ }^{2,3,8,13}$ At this writing, only 3 of the 17 patients in CR and 1 patient in PR have relapsed. The results are even more relevant if one considers that all but 3 patients showed at presentation an advanced stage, with a high LDH value in half of them (50\%), bone marrow involvement in $41 \%$, and an age older than 60 years in one-third of patients. All these parameters have been shown to have adverse prognostic significance in the prognostic index for peripheral T-cell lymphoma unspecified (the so-called PIT model). ${ }^{4}$ Indeed, the median CR duration of 11 months looks quite promising if one considers that almost half of the patients with PTCL die because of their disease within 1 year following conventional treatments. ${ }^{4}$ Although the numbers in this study were very small, the patients treated with $8 \mathrm{CHOP}-\mathrm{C}$ courses seemed to respond better than the ones treated with 4 CHOP-C courses: $33 \%$ versus $76 \%$, respectively. This outcome could suggest that the second schedule is the efficacious one, and could prompt us to plan a future treatment schedule with CHOP-C 21 or even CHOP-C 14 instead of CHOP-C 28.

The histopathologic diagnosis was carefully reviewed in all patients, with additional immunohistochemical studies in most diagnostic samples. In addition, expression of CD52 was assessed whenever possible. In our series, 11 of 15 evaluable patients had neoplastic cells positive for CD52, with a higher percentage than those found by Rodig et $\mathrm{al}^{22}$ and Piccaluga et al. ${ }^{43}$ It has been reported that CD52 expression might correlate with treatment outcome in T-PLL. ${ }^{21}$ However, we could not show any relationship between CD52 expression and treatment outcome in our series, but this might reflect the limited number of patients enrolled. The same holds true for the CD52 positivity prevalence among patients with PTCL recorded in the present study: for instance, Piccaluga et al-who obtained much lower figures-evaluated 93 patients. ${ }^{43}$ Thus, prospective studies on larger collectives are warranted to understand predictive value of CD52 determination. Our results might indicate that the intensity rather than the percentage of CD52 expression by neoplastic cells is relevant and may predict tumor response to alemtuzumab. This hypothesis is supported by recent in vitro observations in experimental models. ${ }^{44}$ Alternatively, one can speculate that alemtuzumab might eliminate surrounding normal $\mathrm{CD}_{2}{ }^{+}$cells, leading to damage to the microenvironment and, as a consequence, to a weakened survival of neoplastic cells. Whatever the mechanisms, the combination of alemtuzumab and $\mathrm{CHOP}$ represents an innovative and really effective treatment for a disease poorly responsive to currently available therapies.

Despite a thorough program of anti-infective prophylaxis and watchful clinical monitoring, the main problem we faced in our study was the high incidence and severity of infectious complica- tions. Indeed, life-threatening infections occurred in one-quarter of the patients ( 2 instances of invasive aspergillosis, 1 instance of J-C viral encephalitis, 2 instances of sepsis, 2 instances of pneumonia, and 1 instance of suspected tuberculosis). The total and differential T-cell counts were not checked cycle by cycle in all the patients: in 3 patients, the CD3 values dropped below 500 cells/ $\mu \mathrm{L}$ after the third course of chemotherapy: for these reasons the severe $\mathrm{T}$ depletion could reasonably be the main cause for these serious infections. These numbers confirm that alemtuzumab therapy is associated with marked immunosuppression and consequently with an increased risk of infections by various agents, as already observed in previous experiences with alemtuzumab in patients with T-cell disorders. ${ }^{38-39,41}$ Moreover, in a few patients, transient severe neutropenia or even pancytopenia were observed; however, incidence, degree, and duration were similar to those reported in previous studies with alemtuzumab in PTCL. ${ }^{38,39,41}$ In fact, the main toxicity associated with alemtuzumab is probably the suppression of T-cell function and the absolute drop in the number of CD4 cells. These factors are responsible for the opportunistic infections that remain the most serious problem during and after alemtuzumab administration. Attempts to minimize the risk of infectious complication, using new strategies such as preemptive therapies based on a very early diagnosis of viral or fungal infection and/or the infusion of cytotoxic $\mathrm{T}$ lymphocytes (CTLs) raised against specific viral or fungal targets should be possibly considered and included in alemtuzumab-containing programs. ${ }^{45-46} \mathrm{~A}$ number of new drugs less immunosuppressive are at present under evaluation in PTCL: among these are gencytabine alone ${ }^{47}$ or in combination, ${ }^{48}$ the histone deacetylase inhibitors depsipeptide ${ }^{49}$ and SAHA, ${ }^{50}$ the purine analog nelarabine, ${ }^{51}$ and new antifolate drugs such as pralatrexate. All these drugs showed a mild to moderate activity in PTCL, with the noteworthy exception of pralatrexate: the latter, in a phase 2 pilot study, was able to induce CR in 4 out of 5 patients with heavily pretreated PTCL. Of the 4 responding patients, 3 remained in CR for 4 to 9 months, with no other side effects than a mild stomatitis. ${ }^{52}$

In conclusion, the results of our prospective trial demonstrate that CHOP-C is a practicable and effective regimen for patients with PTCL at diagnosis, inducing a high rate of CR; its efficacy, however, could be potentially hampered by the nonnegligible percentage of infectious complications reported in this study: at this writing, a number of phase 3 randomized trials comparing CHOP-C followed by ASCT to traditional CHOP or CHOP-like regimens followed by the same intensive regimen are under way. Only these randomized trials could clarify the confines of the risk-benefit ratio of this combination regimen. Recently encouraging results in terms of OS and PFS have been reported using reduced-intensity conditioning (RIC) allogeneic transplantation in patients with relapsed or primary refractory PTCLs. ${ }^{53}$ Based on these findings, it has been suggested that patients with an HLAidentical donor and poor prognostic features at diagnosis might be included in investigative trials of RIC, followed by allografting. However, an adequate tumor reduction if not a complete remission is a prerequisite for a successful allogeneic procedure. Thus, CHOP-C can be considered a suitable up-front treatment for PTCLs that ensures a high response rate; responsive patients with an adverse prognostic presentation and an HLA-identical donor may subsequently be considered for RIC allograft. This combined approach is now under evaluation in an ongoing multicenter study at our institutions in Italy. 


\section{Acknowledgments}

We thank Cristina Campidelli from the pathology chair of the University of Bologna for having cooperated in the pathology review of the diagnostic material.

This work was supported in part by research funding from Schering AG to A.G.

\section{Authorship}

Contribution: A.G. designed research and wrote the paper; C.T. designed research and reviewed the paper; F.Z. reviewed the paper; P.T. analyzed the data; S.P. reviewed the histopathology and reviewed the paper; and all the authors but S.P. and P.T. collected clinical data.

A complete list of the participating institutions in Gruppo Italiano Terapie Innovative nei Linfomi can be found in the Appendix.

Conflict-of-interest disclosure: The authors declare no competing financial interests.

Correspondence: Dr. Andrea Gallamini, Hematology Department, Azienda Ospedaliera S. Croce e Carle Via M Coppino, 26-12100 Cuneo, Italy. email: gallamini.a@ospedale.cuneo.it.

\section{Appendix}

Gruppo Italiano Terapie Innovative nei Linfomi (GITIL) Membership: P. Leoni and M. Montanari: University Division of Hematology at Torrette Hospital, Ancona, Italy; S. Rambaldi and T. Barbui: Division of Hematology at Ospedali Riuniti, Bergamo, Italy; S. Cortelazzo: Division of Hematology at Ospedale Santa Maurizio, Bolzano, Italy; G. La Nasa: University Division of Hematology at Ospedale Binaghi, Cagliari, Italy; F. Di Raimondo and G. Palumbo: University Division of Hematology at Ospedale Ferrarotto, Catania, Italy; A. Gallamini: Division of Hematology at Ospedale Santa Croce, Cuneo, Italy; A.M. Gianni: University Division of Oncology at Istituto Nazionale per la cura dei Tumori (INT), Milan, Italy; P. Corradini: University Division of Hematology at Istituto Nazionale per la cura dei Tumori (INT), Milan, Italy; F. Ciceri: University Division of Hematology at Istituto di Ricovero e Cura a Carattere Scientifico (IRCCS) Ospedale San Raffaele, Milan, Italy; G. Semenzato: University Division of Hematology, Milan, Italy; S. Mirto and C. Patti: Division of Hematology at Ospedale Vincenzo Cervello, Palermo, Italy; B. Falini and M. Martelli: University Division of Hematology at Policlinico Monteluce, Perugia, Italy; A. Olivieri: Division of Hematology at Ospedale San Carlo, Potenza, Italy; I. Majolino and V. Zoli: Division of Hematology at Ospedale San Camillo/Forlanini, Rome, Italy; S. Amadori and M. Cantonetti: University Division of Hematology at Torvergata University, Rome, Italy; G. Saglio and G. Parvis: University Division of Internal Medicine at San Luigi Hospital, Orbassano [Torino], Italy; C Tarella and M. Ladetto: University Division of Hematology at San Giovanni Hospital, Torino, Italy; G. Pizzolo and F. Benedetti: University Division of Hematology, University and Hospital of Verona, Italy.

\section{References}

1. Coiffier B, Berger F, Byron PA, et al. T-cell lymphomas: immunological, histological, clinical and therapeutic analysis of 63 cases. J Clin Oncol. 1988;6:1584-89.

2. Ascani S, Zinzani PL, Gherlinzoni F, et al. Peripheral T-cell lymphomas: clinico-pathologic study of 168 cases diagnosed according to the R.E.A.L. classification. Ann Oncol. 1997;8:583-92.

3. Jaffe ES, Harris NL, Stein H, Vardiman JW. Tumours of haematopoietic and lymphoid tissue. In: Pathology \& Genetics. Lyon, France: IARC Press 2001:189-235.

4. Gallamini A, Stelitano C, Calvi R, et al. Peripheral T-cell lymphoma unspecified (PTCL-U): a new prognostic model from a retrospective multicentric clinical study. Blood. 2004;103:2474-2479.

5. Cheng AL, Chen YC, Wang $\mathrm{CH}$, et al. Direct comparison of peripheral T-cell lymphoma with diffuse B-cell lymphoma of comparable histological grades: should peripheral T-cell lymphoma be considered separately? J Clin Oncol. 1989;7:725

6. Kwak LW, Wilson M, Weiss LM, et al. Similar outcome of treatment of B-cell and T-cell diffuse large cell lymphomas: the Stanford experience. J Clin Oncol. 1991;9:1426-33.

7. Coiffier B, Brousse N, Peuchmaur M, et al. Peripheral T-cell lymphomas have a worse prognosis than B-cell lymphomas: a prospective study of 361 immunophenotyped patients treated with the LNH84 regimen. Ann Oncol. 1990;1:45-50.

8. Melnyk A, Rodriguez A, Pugh WC, Cabanillas F. Evaluation of the revised European-American lymphoma classification confirms the clinical relevance of immunophenotype in 560 cases of aggressive non-Hodgkin's lymphoma. Blood. 1997; 89:4514-20.

9. Gisselbrecht C, Gaulard P, Lepage E, et al. Prognostic significance of T-cell phenotype in aggressive non-Hodgkin's lymphomas Blood. 1998;92: 76-82.

10. Lopez-Guillermo A, Cid J, Salar A, et al. Peripheral T-cell lymphomas: initial features, natural his- tory and prognostic factors in a series of 174 patients diagnosed according to the R.E.A. L. classification. Ann Oncol. 1998;9:849-55.

11. Ansell SM, Habermann TM, Kurtin PJ, et al. Predictive capacity of the International Prognostic Factor Index in patients with peripheral T-cell lymphomas. J Clin Oncol. 1997;15:2296-301.

12. Zaja F, Russo D, Silvestri F, et al. Retrospective analysis of 23 cases with peripheral T-cell lymphoma, unspecified: clinical characteristics and outcome. Haematologica. 1997;82:171-77.

13. Rudiger T, Weisenburger DD, Anderson JR, et al. Peripheral T-cell lymphoma (excluding large-cell lymphoma): results from the Non-Hodgkin's Lym phoma Classification Project. Ann Oncol. 2002; 13:140-149.

14. Haioun C, Lepage E, Gisselbrecht C, et al. Benefit of autologous bone marrow transplantation over sequential chemotherapy in poor-risk aggressive non-Hodgkin's lymphoma: updated re sults of the prospective study LNH87-2. J Clin Oncol. 1997;15:1131-37.

15. Rodriguez J, Munsell M, Yazji S, et al. Impact of high-dose chemotherapy on peripheral T-cell lymphomas. J Clin Oncol. 2001;19:3766-3770.

16. Rodriguez J, Caballero MD, Gutierrez A, et al. High dose chemotherapy and autologous bone marrow transplantation in patients with periphera T-cell lymphoma not achieving complete response after induction chemotherapy: the GELTAMO experience. Haematologica. 2003;88: 1372-1377.

17. Rodriguez J, Caballero MD, Gutierrez A, et al. High-dose chemotherapy ant autologous stem cell transplantation in peripheral T-cell lymphoma: the GEL-TAMO experience. Ann Oncol. 2003;14: 1768-1775.

18. Jantunten E, Wilkund T, Juvonen E, et al. Autologous stem cell transplantation in adult patients with peripheral T-cell lymphoma: a nation-wide survey. Bone Marrow Transplant. 2004:33:405410

19. Kewalramani T, Zelenetz AD, Teruya-Feldstein J, et al. Autologous transplantation for relapsed or primary refractory peripheral T-cell lymphoma. Br J Haematol. 2006;134:202-207.

20. Corradini P, Tarella C, Zallio E, et al. Long-term follow-up of patients with peripheral T-cell lymphomas treated up-front with high-dose chemotherapy followed by autologous stem cell transplantation. Leukemia. 2006;20:1533-1538.

21. Ginaldi L, De Martinis M, Matutes E, et al. Levels of expression of CD 52 in normal and leukemic $B$ and T cells: correlation with in vivo therapeutic responses to Campath-1H. Leuk Res. 1998;22: 185-191.

22. Rodig SJ, Abramson JS, Pinkus GS, et al. Heterogeneous CD52 expression among hematologic neoplasms: implications for the use of alemtuzumab (CAMPATH-1H). Clin Cancer Res. 2006; 12:7174-7179.

23. Sabattini E, Bisgaard K, Ascani S, et al. The EnVision++ system: a new immunohistochemical method for diagnostics and research: critical comparison with the APAAP, ChemMate, CSA $\mathrm{LABC}$, and SABC techniques. J Clin Pathol. 1998:51:506-511.

24. Went P, Agostinelli C, Gallamini A, et al. Marker expression in peripheral T-cell lymphoma: a proposed clinical-pathologic prognostic score. J Clin Oncol. 2006;24:2472-2479.

25. Fisher IF, Gaynor EL, Martin D, et al. Comparison of a standard regimen (CHOP) with three intensive chemotherapy regimens for advanced NonHodgkin's Lymphoma. N Engl J Med. 1993;328: 1002-1006.

26. A'Hern RP. Sample size tables for exact singlestage phase II designs. Stat Med. 2001;20:859866.

27. Oken MM, Creech RH, Tommey DC, et al. Toxic ity and response criteria of the Eastern Cooperative Oncology Group. J Clin Oncol. 1982;5:649655.

28. Cheson BD, Horning SJ, Coiffier B, et al. Report 
From bloodjournal.hematologylibrary.org at Biblioteche biomediche Università di Torino on May 18, 2012. For

of an International workshop to standardize response criteria for non-Hodgkin's lymphoma. J Clin Oncol. 1999;17:1244-1253.

29. SAS 9.1.3 user's guide: help and documentation. Cary, NC: SAS Institute; 2000-2004.

30. Kaplan EL, Meier P. Nonparametric estimation from incomplete observation. JAMA. 1958;53: 457-481.

31. Hryniuk W, Bush H. The importance of dose intensity in chemotherapy of metastatic breast cancer. J Clin Oncol. 1984;2:1281-1288.

32. Savage K. Aggressive peripheral T-cell lymphoma (specified and unspecified types). Hematology. Am Soc Hematal Educ Program. 2005 267-277.

33. Reimer P, Rudiger T, Wilhelm M. The role of highdose therapy in peripheral T-cell lymphoma. Clin Lymphoma Myeloma. 2006;6:373-9.

34. Hiddemann W, Buske C, Dreyling M, et al. Treatment strategies in follicular lymphomas: current status and future perspectives. J Clin Oncol. 2005;23:6394-9.

35. Tarella C, Gianni AM. BMT for lymphoma CR1. Curr Opin Oncol. 2005;17:99-105.

36. Gisselbrecht C, Mounier N. Managing large cell lymphoma: symposium article. Ann Oncol. 2006; 17:iv4-iv11.

37. Dearden C. The role of Alemtuzumab in the management of T-cell malignancies. Sem. Oncol. 2006;33:S44-S52.

38. Dearden C, Matutes E, Cazin B, et al. High remission rate in T-cell prolymphocytic leukemia with CAMPATH-1H. Blood. 2001;98:1721-1726.
39. Lundin J, Hagberg H, Repp L, et al. Phase 2 study of alemtuzumab (anti-CD52 monoclonal antibody) in patients with advanced mycosis fungoides/Sezary syndrome. Blood. 2003;101:42674272.

40. Osuji N, Del Giudice I, Matutes E, et al. CD52 expression in T-cell large granular lymphocytic leukemia: implications for treatment with alemtuzumab. Leuk Lymphoma. 2005;46:723-727.

41. Emblad G, Hagberg H, Ertanson M, et al. A pilot study of alemtuzumab (anti-CD52 monoclonal antibody) therapy for patients with relapsed or chemotherapy-refractory peripheral T-cell lymphoma. Blood. 2004;103:2920-2924.

42. Kim JG, Sohn SK, Chae YS, et al. Alemtuzumab plus CHOP as front-line chemotherapy for patients with peripheral T-cell lymphomas: a phase II study. Cancer Chemother Pharmacol. 2007;1: 129-134.

43. Piccaluga PP, Agostinelli C, Righi S, et al. Expression of CD52 in peripheral T-cell lymphoma. Haematologica. 2007;92:566-567.

44. Golay J, Manganini M, Rambaldi A, et al. Effect of alemtuzumab on neoplastic B cells. Haematologica. 2004;89:1476-1483.

45. Maertens J, Verhaegen L, Lagrou K, et al. Screening for galactomannan as a noninvasive diagnostic tool for invasive aspergillosis in prolonged neutropenic patients and stem cell transplantation recipients: a prospective validation. Blood. 2001;97:1604-1610.

46. Ramadan G, Davies B, Kurup VP, et al. Generation of Th1 T cell responses directed to a HLA class II restricted epitope from the aspergillus $\mathrm{f} 16$ allergen. Clin Exp Immunol. 2005;139:257-267.

47. Sallah S, Wan JY, Nguyen NP. Treatment of refractory T-cell malignancies using gemcitabine. Br J Haematol. 2001;113:185-187.

48. Arkenau HT, Chong G, Cunningham D, et al. Gemcitabine, cisplatin and methylprednisolone for the treatment $f$ patients with peripheral T-cell lymphoma: the Royal Marsden Hospital experience. Haematologica. 2007;92:271-272.

49. Piekarz RL, Frye R, Turner M, et al. Responses and molecular markers in patients with peripheral T-cell lymphoma treated on a phase II trial of depsipeptide, FK228. Proc Annu Meet Am Assoc Cancer Res. 2005;24:3061.

50. O'Connor OA, Heaney M, Schwartz L, et al. Clinical experience with intravenous and oral formulations of the novel histone deacetylase inhibitor suberoylanilide hydroxamic acid in patients with advanced hematologic malignancies. J Clin Oncol. 2006;24:166-173.

51. Czuczman MS, Porcu PL, Johnson J, et al. Results of a phase II study of $506 \mathrm{U} 78$ in cutaneous T-cell lymphoma and peripheral T-cell lymphoma: CAGB 59901. Leuk Lymphoma. 2007;48:97-103.

52. O'Connor OA: Pralatrexate: an emerging new agent with activity in T-cell lymphomas Corr Opin Oncol. 2006;18:591-597.

53. Corradini P, Dodero A, Zallio F, et al. Graft-versus-lymphoma effect in relapsed peripheral T-cell non-Hodgkin's lymphomas after reduced-intensity conditioning followed by allogeneic transplantation. J Clin Oncol. 2004;22:2172-2176. 